\title{
3D Conceptual Modelling and Direct Utilization Calculations of the Albanian Geothermal Resources
}

\author{
Nevton Kodhelaj ${ }^{1}$, Aida Bode ${ }^{2}$ \\ ${ }^{1}$ Department of Energy Resources, Faculty of Geology and Mining, Polytechnic University, Tirana, Albania \\ ${ }^{2}$ Department of Natural Resources, Faculty of Geology and Mining, Polytechnic University, Tirana, Albania \\ Email: nevtonkodheli@yahoo.com,boaal@yahoo.com
}

Received 2013

\begin{abstract}
Balneological use of the Albanian Geothermal springs and waters dates back centuries, but the first modern use started in 1937. Unfortunately they had not been used for its energetic values yet. The temperature of the water is above $60^{\circ} \mathrm{C}$ and the flow above $16 \mathrm{l} / \mathrm{s}$, thus direct utilization is possible, in particular for space heating. Three-dimensional temperature field calculations and engineering calculations on a heating system with heat exchangers are presented here. The results show that the water temperature is expected to be stable and considerably higher temperature is expected through deep well drilling. The University's Campus of Tirana is composed of 29 buildings, which are partially heated through a coal heater. The installed capacity is $2558 \mathrm{~kW}$ while the coal consumption is about $920 \mathrm{~kg} / \mathrm{h}$. The University's Campus of Tirana is one of the most important areas and with the highest density of population in Tirana, so it is the best area to show the heat exchanger efficiency. The economic analyses prove that the borehole heat exchangers are more convenient than the coal heating systems.
\end{abstract}

Keywords: Geothermal; Temperature Field; Modelling; Radiators; Wells; Borehole Heat Exchangers

\section{Introduction}

Albania is a small country of only $28787 \mathrm{~km}^{2}$ surface area and around 4500000 inhabitants, situated in the southwest part of the Balkan Peninsula, next to the boundary of the African and the Euro-Asiatic plates. This setting makes the presence of geothermal resources possible. Surface manifestations of geothermal resources are found throughout Albania, ranging from the region of Peshkopia in the northeast, where hot springs with water temperature of about $43^{\circ} \mathrm{C}$ and inflow above $14 \mathrm{l} / \mathrm{s}$ are found, through the central part of the country with different sources (including the springs of Llixha-Elbasan) with temperatures above $66^{\circ} \mathrm{C}$, to the Peri-Adriatic depression with a number of wells (drilled for oil and gas research) producing water with temperatures around $40^{\circ} \mathrm{C}$ with variable yields. The thermal waters in Albania are only used for balneology. This form of use dates back to early in history, or to the time of the Roman Empire (i.e. the Sarandaporo's thermal baths). So far, the geothermal resources have not been utilized for other purposes, such as for their energetic values. Estimated temperature measurements based on different geothermometers indicates that the temperature of the waters in the formation of the Llixha reservoir may be above $220^{\circ} \mathrm{C}$. The reservoir is believed to be in the depth interval of
4500-5000 m. Tirana's geothermal heat sources are:

- Underground waters of the Tirana quaternary depression;

- Underground waters of the tortonian's sandstones;

- Heat of the peri-superficial quaternary or tortonian layers;

- Limestone's and dolomites saturated with artesian waters.

- The following is addressed in the material:

- The general geological conditions in the areas;

- A review of the theoretical basis of heat transfer;

- Finite-volume modeling of the whole geothermal system down to $5000 \mathrm{~m}$ depth, incorporating both thermal convection and conduction, based on a simple boundary conceptual model;

- House heating calculations;

- Borehole heat exchangers calculations;

- Economic analyses.

All this aims at demonstrating that the thermal water flowing from the Llixha springs is usable for direct utilization and the borehole heat exchangers heating systems are economically feasible, despite their elevated preliminary cost. This utilization would diversify the energy resources, mitigate the electricity supply the region, help improve living conditions for the local community and protect the environment of the region. 


\section{Geological Background of the Llix- ha-Elbasan and Tirana Region}

\subsection{The Geological Structure of Llixha Region}

The Llixha region is situated southwest of Elbasan. The region is well known for its thermal springs, appreciated since ancient times for their curative properties. The region under study is south of Shkumbini river valley. The surface relief increases rapidly up to intermediate elevation $(300-500 \mathrm{~m})$. In the western part of the region, a system of hills declines gradually in the Cërriku field. The region has a rich hydro system of small streams and many underground water-systems. The flow rate for the underground waters varies from 100-200 l/h in Thanë up to $5000 \mathrm{l} / \mathrm{h}$ in Tregan. This is an inhabited area, with small villages clustered around the thermal waters no more than 2-3 km from each other [2,6]. The region lies between two tectonic regions; the transversal Vlorë-Elbasan-Dibër and the longitudinal Leskovik-Drini river bay. In the context of Albanian tectonics, the region represents the western part of the Kruja tectonic zone. The orientation of these structures is SW-NE as is the rest of the Albanides structure [1,6]. The lowest part of the formation is composed of thinner flysch units intercalated by clays and sandstone, while the upper part is composed of thicker flysch with conglomerates. The Llixha syncline represents a depressed structure with eastern asymmetry filled in the central part with terygen, flysch and molasses deposits. The eastern part is distinguished by an easterly drop. The tectonics put the upper deposits in contact with the lower flysch Oligocene formation and has made the surface intrusion of the Eastern anticline calcareous formations possible; it is regional and includes the Western anticline chain of the Kruja tectonic zone (Hyseni and Milo, 2000). The Llixha system comprises a reservoir which feeds the southern part of the Shkumbini River. he main hydrological characteristic of the region is the presence of several hot springs. The temperature of the hot springs varies, ranges from 50 to $68^{\circ} \mathrm{C}$ while flow rates vary from one spring to another, without any seasonal characteristics.

\subsection{The Geological Structure of Tirana Region}

Tirana aquifer is related with the syncline deposits of Tirana, whose morphology represent a depression of 10 $12 \mathrm{~km}$ of width and 70-80 km of length. Wells yield in the region varies between 7-10 l/s, while for the Tortonians molasses the wells yield is about 3-4 l/s.

\section{Heat transfer Theory}

\subsection{The Differential Equation for Heat Transfer}

This equation is a mathematical expression of the first law of thermodynamics, the energy preservation low. The heat increase of an elementary volume $\Delta V$ is equal with the thermal energy which crosses the surface $S$. A solid medium is considered, which is not generating any energy (so the energy is only flowing through a surface $S)$. The temperature $T$ at a point $P(x, y, z)$ will be a continuous function of the position and time. For a homogenous solid medium, in which the thermal volume heat capacity is independent of temperature, the equation is [2, 3]:

$$
\nabla^{2} T=\frac{\partial^{2} T}{\partial x^{2}}+\frac{\partial^{2} T}{\partial y^{2}}+\frac{\partial^{2} T}{\partial x^{2}}=\frac{1}{a} \frac{\partial T}{\partial t}
$$

\subsection{The Basics Hypothesis}

In order to solve the thermal diffusion equation let's assume that the formation temperature is function of the position $(x, y, z)$ and time $(t)$ [3]. In additions initial and boundary conditions must be specified. A specific moment of time is chosen as the origin of the time coordinate. At that time the temperature distribution is:

$$
\begin{aligned}
T(x, y, z, t=0 \neq f(x, y, z) \\
o \quad T(r, \theta, z, t=0 \neq f(r, \theta, z)
\end{aligned}
$$

The radials symmetric case of a flowing wellbore is considered, as an example. After a certain production time the well is shut down. To determine the temperature distribution in the wellbore during the shutdown time, the end of production is considered as the origin of the time coordinate. In this case the temperature $f(r, z)$ must be known, i.e. the initial conditions. To specify the temperature field of a medium the boundary conditions must also be known beforehand. Different kinds of boundary conditions can be specified:

- Surface temperature is known. It can be constant or function of position and time, $\mathrm{T}=f(x, y, z, t)$

- The amount of energy flowing through the surface is known:

$$
q_{s}(x, y, z, t)=-\lambda \frac{\partial T}{\partial n}
$$

$\left\{\frac{\partial}{\partial n}=\right.$ the derivation perpendicular to the surface $\}$

- Linear surface heat flow. In such a case the amount of energy transmitted through a given surface is proportional with the temperature difference between the surfaces and the surroundings:

$$
q_{s}=\alpha\left(T_{s}-T_{0}\right)
$$

The connecting surface between two media with conductivity $\lambda_{1}$ and $\lambda_{2}$, respectively. If $T_{1}$ and $T_{2}$ are the temperatures of the media, then: 


$$
\left.T_{1}\right|_{s}=\left.T_{2}\right|_{s}-\left.\lambda_{1} \frac{\partial T_{1}}{\partial n}\right|_{s}=-\left.\lambda_{2} \frac{\partial T_{2}}{\partial n}\right|_{s}
$$

\subsection{The Unstable Temperature Field}

Before starting investment in a geothermal project, the stability of the temperature field involved, in space and time, needs to be confirmed as well as the projects overall sustainability. The methods that can be used to answer such questions are numerous, but here we will apply the finite element method (Osmani, 1997). Considering the differential equation:

$$
\begin{aligned}
& \frac{\partial}{\partial x}\left(k_{x} \frac{\partial T}{\partial x}\right)+\frac{\partial}{\partial y}\left(k_{y} \frac{\partial T}{\partial y}\right)+\frac{\partial}{\partial z}\left(k_{z} \frac{\partial T}{\partial z}\right) \\
& +q(x, y, z)-c \frac{\partial T}{\partial t}=0
\end{aligned}
$$

The functional of this equation is (Osmani, 1997):

$$
\begin{aligned}
X= & X_{v}+X_{r} \\
= & \iint_{\Omega}\left[\frac{k_{x}}{2}\left(\frac{\partial T}{\partial x}\right)^{2}+\frac{k_{y}}{2}\left(\frac{\partial T}{\partial y}\right)^{2}+\frac{k_{z}}{2}\left(\frac{\partial T}{\partial z}\right)^{2}\right] d x d y d z \\
& +\iiint_{\Omega}\left(q-c \frac{\partial T}{\partial t}\right) d x d y d z
\end{aligned}
$$

To integrate the Equation (7) let's assume the time interval $(t, t+\Delta t)$ through into $d T / d t=C\left(T_{i}\right.$ temperature values in the nodes $I=1,4)$.

$$
\begin{aligned}
& \frac{\partial X}{\partial T_{i}}=\frac{\partial X_{v}}{\partial T_{i}}+\frac{\partial X_{r}}{\partial T_{i}} ; \text { where } i=\overline{1,4} \\
& T=\frac{1}{6 \Delta}\left\{\begin{array}{llll}
N_{1} & N_{2} & N_{3} & N_{4}
\end{array}\right\}\left\{\begin{array}{l}
\overline{T_{1}} \\
\frac{T_{2}}{T_{3}} \\
T_{4}
\end{array}\right\} ; \\
& N_{i}(x, y, z)=\left(a_{i}+b_{i} x+c_{i} y+d_{i} z\right)
\end{aligned}
$$

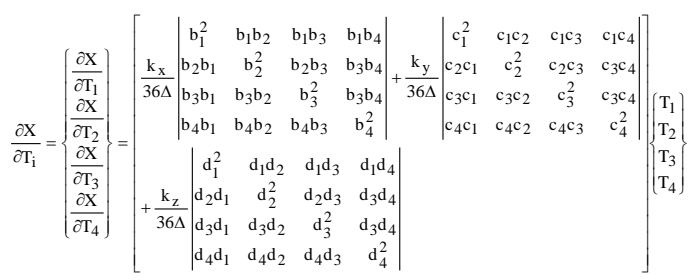

$$
\begin{aligned}
& \iiint \mathrm{N}_{1}^{2} d x d y d z \quad \iiint \mathrm{N}_{1} \mathrm{~N}_{2} d x d y d z \quad \iiint \mathrm{N}_{1} \mathrm{~N}_{3} d x d y d z \quad \iint \mathrm{N}_{1} \mathrm{~N}_{4} d x d y d z
\end{aligned}
$$

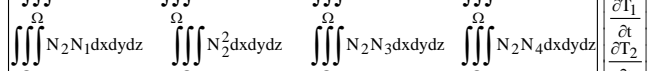

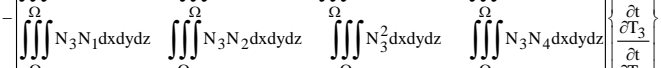

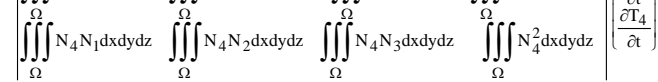

$$
\begin{aligned}
& -\frac{\mathrm{Q} \Delta}{4}\left\{\begin{array}{l}
1 \\
1 \\
1 \\
1
\end{array}\right\}=\left\{\begin{array}{l}
0 \\
0 \\
0 \\
0
\end{array}\right\}
\end{aligned}
$$

Using the numerical transformations the Equation (6) is transformed as follows:

$$
|H||T|+|P| \frac{\partial T}{\partial t}-|F(t)|=0
$$

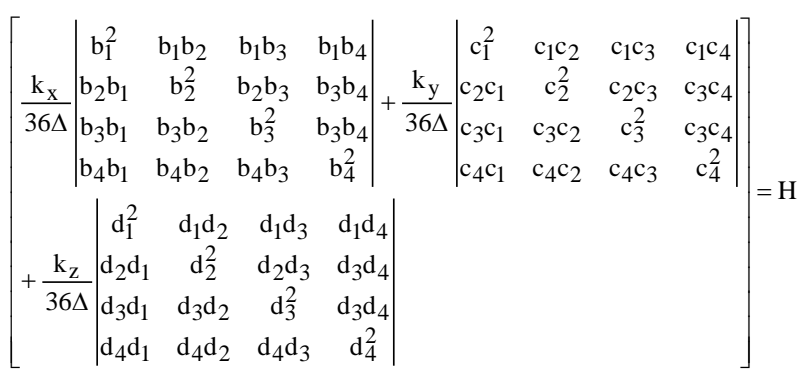

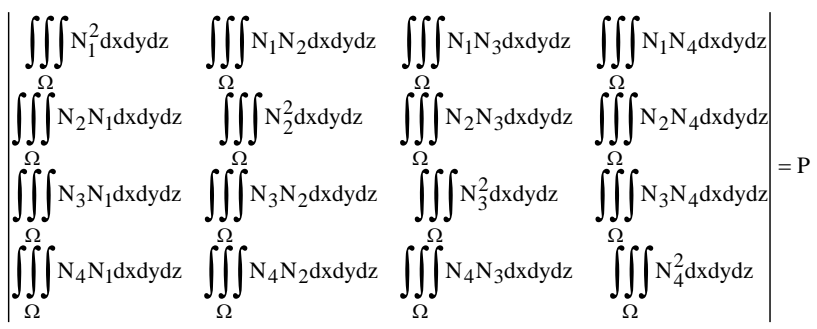

$\frac{\mathrm{Q} \Delta}{4}=\mathrm{F}$

\section{District Heating System Using the Geothermal Water}

In general the geothermal water for districts heating systems is taken directly from low temperature reservoirs. Another way is the use the geothermal water through the heat exchangers to heat up the fresh water. The hot water can be stored in tanks if appropriate. This water than is transmitted to the buildings and can be used for heating and tap water. Heat flow to the buildings is controlled by the mass flow. In the following are given the basics calculations for the geothermal district heating. The main elements of the geothermal district heating are the radiators and also this use is affected by the water thermal energy, building heat loss, pipe heat loss and building energy storage.

\subsection{Borehole Heat Exchangers}

The equation for rate of heat transfer from the fluid in the heat exchanger to the earth mass is [5, 7]: 


$$
\begin{aligned}
\frac{Q}{L} & =U * \Delta T ; \\
U & =\frac{2 \pi}{\text { Soil resis tan ce }+ \text { Pipe resis tan ce }} \\
& =\frac{2 \pi}{R_{s}+R_{p}} ; \\
\Delta T & =\frac{T_{1}+T_{2}}{2}-T_{0}
\end{aligned}
$$

\subsection{Results of Simple Hot Spring Modelling}

A finite volume model was set up for a crustal volume with an area of $10 \times 10 \mathrm{~km}$ and $5 \mathrm{~km}$ thickness to model the temperature, density and fluid velocity distribution in the Llixha region. Here it is assumed that the medium is homogeneous and isotropic and that $k_{x}=k_{y}=k_{z}=2$ $\mathrm{W} / \mathrm{m}^{\circ} \mathrm{K}$ [8]. We also know that $Q=20 \mathrm{l} / \mathrm{s}$ (corresponding to $m_{i}=Q / 6=3.3 \mathrm{l} / \mathrm{s}$ or $3.224 \mathrm{~kg} / \mathrm{s}$ for each of the hot springs), $c_{p}=4180 \mathrm{~J} / \mathrm{kg}^{\circ} \mathrm{C}$ [2]. The temperature at depth in the formation is set at $221^{\circ} \mathrm{C}$ while the temperature of the water at the surface is in the range $60-65^{\circ} \mathrm{C}$. The temperature gradient of the surroundings is assumed $12^{\circ} \mathrm{C} / \mathrm{km}$. The modeling software FLUENT is use to solve the problem, it provides calculation results for temperature, density and velocity for the volume modeled. In the model water flows with a velocity of $1.25 * 10^{-7} \mathrm{~m} / \mathrm{s}[8,9]$. The results for temperature are shown in the Figure 1.

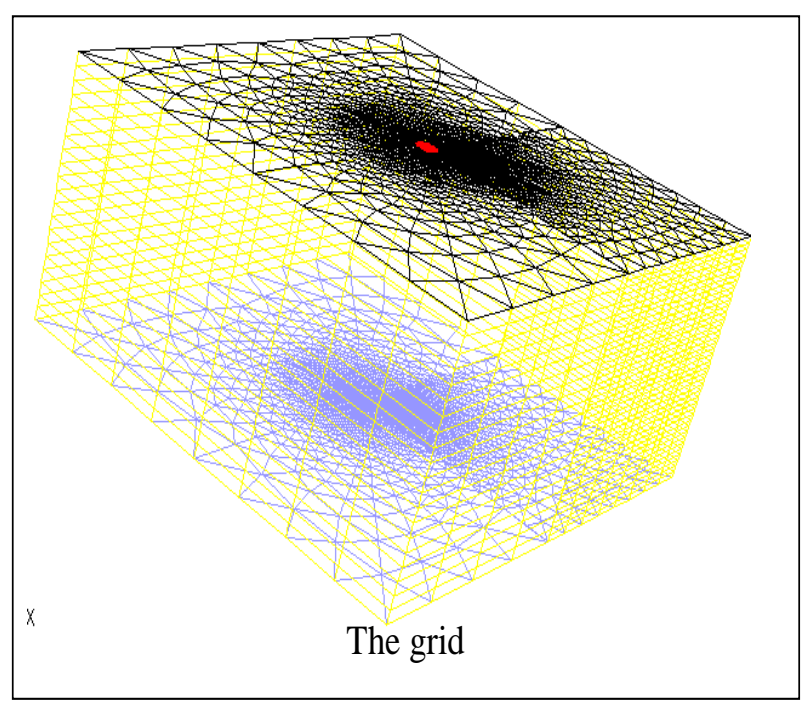

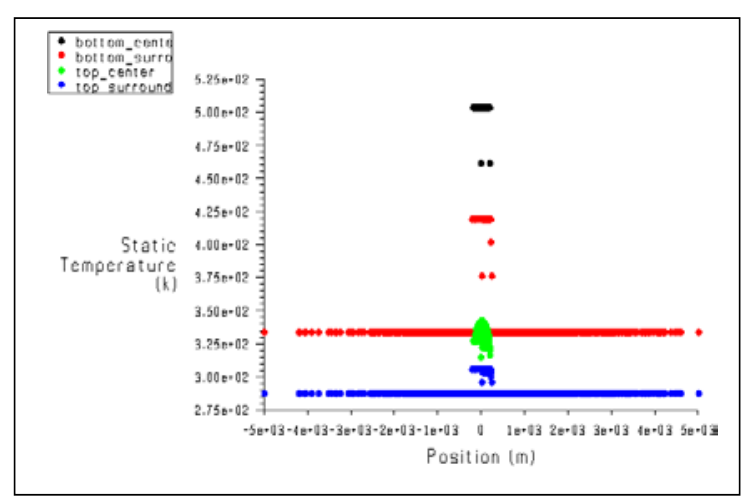

The temperature magnitude

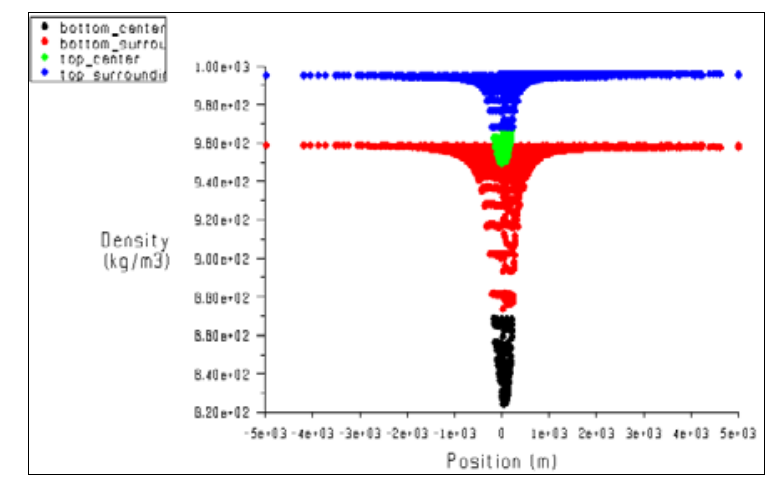

The density magnitude

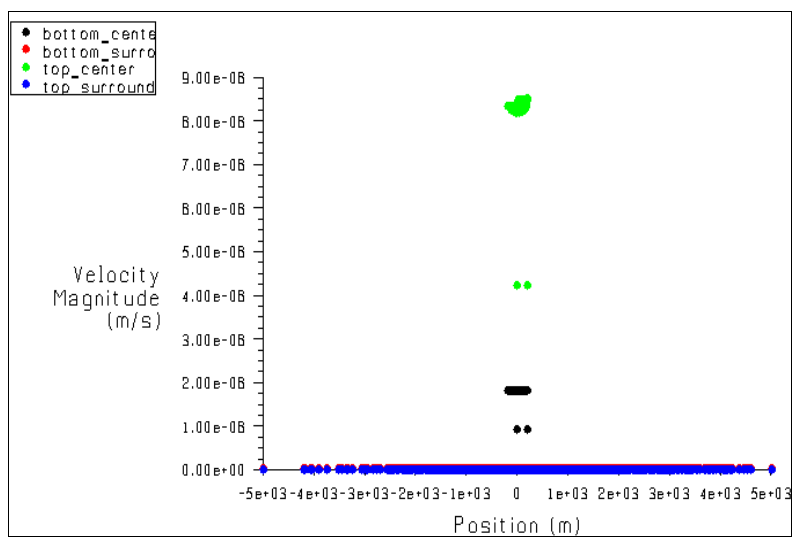

The velocity magnitude

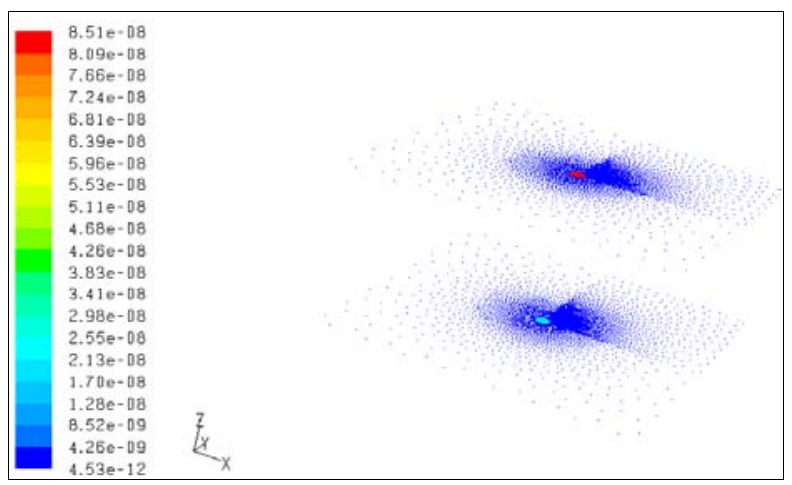

The velocity vectors

Figure 1. Modeling results. 


\subsection{Calculation for the Radiators and BHE}

In these calculations, it was assumed that the supply temperature of the water is $60^{\circ} \mathrm{C}$, the reference temperature $65^{\circ} \mathrm{C}$, the ground temperature $6^{\circ} \mathrm{C}$. The calculations were done for 4 different scenarios: The indoor temperature is assumed to change at the range of $18-20^{\circ} \mathrm{C}$, the outdoor temperature in the range of -10 to $-4{ }^{\circ} \mathrm{C}$, the return water temperature in the range of $33-40^{\circ} \mathrm{C}$, the reference inflow in the range of 3.93-7 kg/s, the reference system inflow 18-24 kg/s. Based on these data, the relative heating of the radiators was calculated as $0.83-0.92$, the relative heating of the building as $0.87-0.88$, and the transmissivity coefficient $\tau=0.94$. To be within these parameters, it is sufficient that the supply water temperature be $60^{\circ} \mathrm{C}$, and the inflow of the system $16-27 \mathrm{~kg} / \mathrm{s}$. Thus the parameters for the Llixha thermal springs satisfy all these demands, Figure 2. According to the measurements, the earth temperature in $100 \mathrm{~m}$ depth in Tirana is $\mathrm{T}_{0}=18^{\circ}$ C. The fluid exit temperature is $3.5^{\circ} \mathrm{C}$ lower than the fluid entry temperature. For these parameters the heat exchangers, for the installed capacity of $100 \mathrm{~kW}$ results that is sufficient the drilling process of 15 wells $100 \mathrm{~m}$ depth each. The economic analyses (profit-expenditure) of three systems: Water-Water geothermal pumps, EarthWater geothermal pump and the existing coal heater are presented in Figure 3. So it can clearly see that the maximal profit is for the Water-Water system than for the Earth-Water and finally for the coal heater. The payback period for the geothermal heating pumps varies from 2.8 up to 10.75 years.

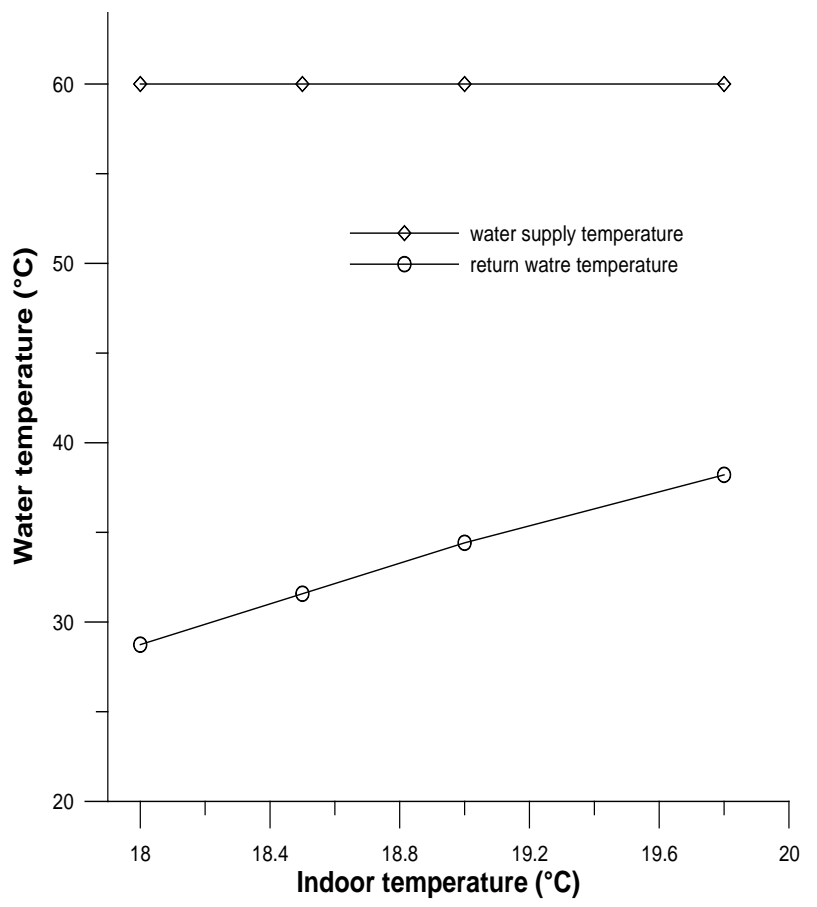

Figure 2. Llixha geothermal springs calculations.

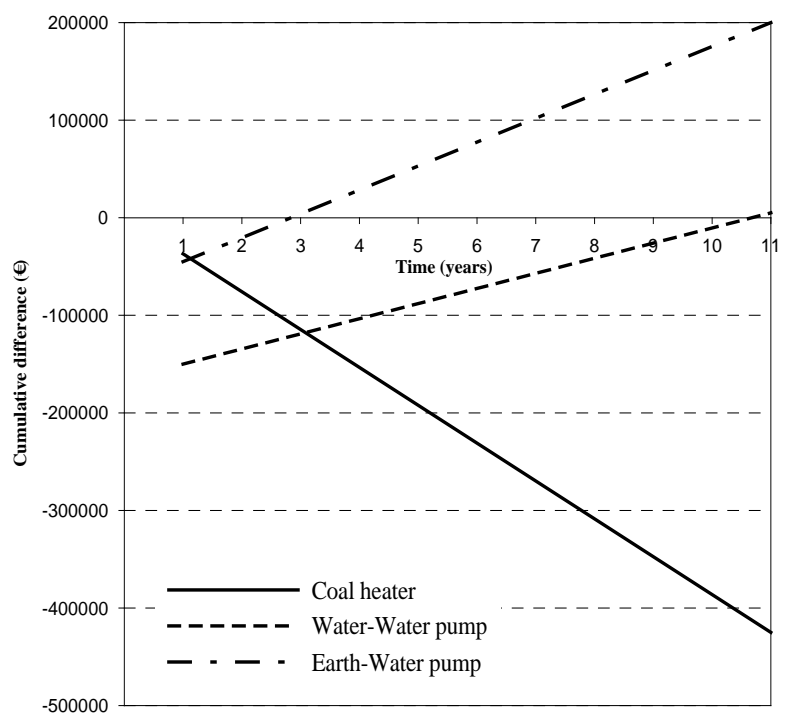

Figure 3. Economic analysis of the BHE.

\section{Conclusions}

- The water temperature is expected to be stable in the future;

- The geothermal water from the Llixha hot springs fulfills all requirements for district heating's in the region;

- $\quad$ Considerably higher temperature expected through further well drilling;

- Albanian geothermal regime allows different scale borehole heat exchangers applications;

- Demographic and geological features of the student's city allow, and furthermore are feasible the borehole heat exchanger's utilization;

- Use of the geothermal waters in Albania is economically feasible and can mitigate the economic problem, improve the living standards of the communities and diversify the energy resources.

\section{REFERENCES}

[1] Aliaj, S., and Hyseni, A., 1996: The neotectonic map of Albania, scale 1:200000. Sh. B. L. U., Tirana, 87 pp.

[2] Buffon, G. L. (1778): Histoire naturelle, générale et particulière.-651 S., De l'imprimerie royale, Paris. Commented edition: Roger, J. (1962): Mémoires du Muséum National d'Histoire Naturelle, Série C, Tome X, Éditions du Muséum, Paris.

[3] Čermak, V., and Haenel, R., 1988: International Association for Seismology and Physics of the Earth's interior, 30-33.

[4] Frashëri, A., and Čermak, V., 2004: The geothermal atlas of Albania. Sh. B. L. U. Tirana, 65-89.

[5] Harlow, J. H. \& Klapper, G. E. (1952): Residential Heat Pump Experiments in Philadelphia-Installation and Operating Experience. - AIEE Trans 71/II, pp. 366-375, New York. 
[6] Hyseni, A., and Melo, V., 2000: The geodynamics of new movements in Albania and their influence in resources and environment. National programmer for research development, Toena, Tirana.

[7] Ingersoll, L. R., Adler, F. T., Plass, H. J. \&Ingersoll, A. C. (1950): Theory of Earth Heat Exchangers for the Heat Pump. - ASHVE Trans. 56, 167-188.
[8] Kodhelaj, N., 2011: Albanian possibilities on geothermal direct utilization. Renewable and sustainable energy review, Elsevier, 15/5, 2011. 2534-2544 pp.

[9] Kodhelaj, N., 2007: The Llixha Elbasan hot springs in Albania, study of temperature conditions and utilization calculations, Reports of the United Nations University, Geothermal Training Programme in 2007, 157-199 pp.

[H] Matrix of conductivity of the thermal field;

\section{Nomenclature}

[P] Matrix of instability of the thermal field;

[F] Source vector;

Q Rate of heat exchanger (BTU/hr or W) for the whole heat exchanger length;

$\mathrm{L}$ length of heat exchanger (m);

$\mathrm{U}$ conductance rate for heat transfer from the circulating fluid to the earth $\left(\mathrm{BTU} / \mathrm{hr} /{ }^{\circ} \mathrm{F}\right.$ or $\mathrm{W} /{ }^{\circ} \mathrm{C} / \mathrm{m}$ ) for the operating conditions;

$\Delta \mathrm{T}$ difference in fluid temperature;

$\mathrm{T}_{0}$ earth temperature $\left({ }^{\circ} \mathrm{F}\right.$ or $\left.{ }^{\circ} \mathrm{C}\right)$;

$\mathrm{T}_{1}$ fluid entry temperature $\left({ }^{\circ} \mathrm{F}\right.$ or $\left.{ }^{\circ} \mathrm{C}\right)$;

$\mathrm{T}_{2}$ fluid exit temperature $\left({ }^{\circ} \mathrm{F}\right.$ or $\left.{ }^{\circ} \mathrm{C}\right)$. 